\title{
Biologia reprodutiva de Cordiera macrophylla (K. Schum.) Kuntze (Rubiaceae), espécie dioica da região sudoeste do Estado de Mato Grosso, Brasil ${ }^{1}$
}

\author{
Simone Santos de Oliveira Cobra ${ }^{2}$, Franciele do Nascimento ${ }^{2}$, Sabrina Aparecida Antoniazzi ${ }^{2}$, \\ Willian Krause ${ }^{3}$, Celice Alexandre Silva ${ }^{3}$ \\ http://dx.doi.org/10.1590/0034-737X201562060002
}

\section{RESUMO}

O gênero Cordiera (Rubiaceae) possui aproximadamente 25 espécies e ampla distribuição no Brasil. Seus representantes são árvores ou arbustos dioicos, com flores funcionalmente unissexuadas. Este estudo foi realizado em dois fragmentos de Floresta Estacional Semidecidual, no município de Tangará da Serra, MT. Foram investigadas a fenologia reprodutiva, a razão sexual, a morfologia e a biologia floral, o sistema e o sucesso reprodutivo. Cordiera macrophylla floresceu de julho a setembro, durante a estação seca, com pico sincrônico entre flores pistiladas e estaminadas. Flores estaminadas florescem antecipadamente e por um período mais prolongado que as pistiladas. A antese das flores pistiladas apresentou maior longevidade. A razão sexual foi de 1:1. Flores estaminadas são dispostas em inflorescências umbeliformes e as pistiladas são unifloras, ambas semelhantes morfologicamente. Os frutos são bagas verrucosas, polispérmicas. A taxa de formação de frutos por polinização natural foi de $95 \%$, evidenciando a dependência dos polinizadores para a manutenção da espécie. O sucesso reprodutivo também foi alto, confirmando que a associação entre morfologia e biologia floral favoreceu a espécie nas áreas estudadas.

Palavras-chave: Biologia e morfologia floral, dioicia, display floral, fenologia de floração, sistema reprodutivo.

\section{ABSTRACT}

\section{Reproductive biology of Cordiera macrophylla (K. Schum.) Kuntze (Rubiaceae), a dioic species of the southwestern Mato Grosso, Brazil}

The gender Cordiera (Rubiaceae) has about 25 species and a wide distribution in Brazil. Its representatives are dioecious trees or shrubs, with functionally unisexual flowers. The study was carried out in two fragments of seasonal semideciduous forest, in the municipality of Tangará da Serra - MT. The reproductive phenology, sex ratio, morphology, and floral biology, as well as the reproductive system and success were investigated. Cordiera macrophylla bloomed in the dry season, from July to September, with synchronous peaks between pistillate and staminate flowers. Staminate bloom earlier and for a longer period than the pistillate flowers. The longevity of anthesis of female flowers was greater. The sex ratio was 1: 1. Staminate flowers are arranged in bell-shaped inflorescences and single-flowered pistillates, and are morphologically similar. The fruits are warty, polyspermic berries. The fruit formation rate by natural pollination was $95 \%$, demonstrating the dependence on pollinators to maintain the species. The reproductive success was also high, confirming that the association between morphology and floral biology favored the species in the studied areas.

Key words: Biology and floral morphology, dioecy, floral display, flowering phenology, reproductive system.

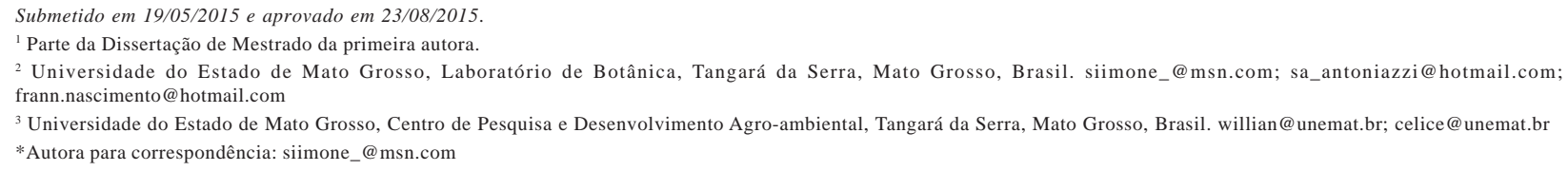




\section{INTRODUÇÃO}

A família Rubiaceae é uma das principais famílias da flora brasileira, posicionada entre as cinco maiores famílias de Angiospermas. Está presente em todos os domínios fitogeográficos no país e conta com 125 gêneros e 1.390 espécies registradas no Brasil (Barbosa et al., 2015).

As plantas da família Rubiaceae apresentam um sistema sexual caracterizado pela presença de indivíduos que produzem flores exclusivamente estaminadas ou pistiladas, a dioicia (Geber et al., 1999). Esta característica está distribuída em cerca $6 \%$ das espécies de Angiospermas de regiões tropicais (Renner \& Ricklefs, 1995).

Flores de espécies arbóreas dioicas tropicais são geralmente pequenas, com coloração variando entre branco e amarelo ou verde claro, adaptadas à visitação e polinização por pequenos insetos generalistas (Bawa \& Opler, 1975), principalmente abelhas sociais (Bawa, 1980).

A dioicia está presente em aproximadamente 110 espécies de Rubiaceae (Yampolsky \& Yampolsky, 1966), inclusive nas pertencentes ao gênero Cordiera (Delprete, 2010). Esse gênero possui cerca de 25 espécies, distribuídas desde o Panamá e a Ilha de Trinidad até a Bolívia e o sul do Brasil, com centro de diversidade no Brasil (Delprete, 2010).

Seus representantes são árvores, arbustos ou subarbustos (Zappi, 2015) que apresentam inflorescências terminais, sendo as masculinas fasciculadas e as femininas unifloras. As flores são actinomorfas e funcionalmente unissexuadas, com frutos formando bagas polispérmicas carnosas (Delprete, 2010). O gênero Cordiera estava incluído em Alibertia, entretanto, estudos filogenéticos evidenciaram a necessidade de seu reconhecimento como um gênero independente (Persson, 2000).

A partir disso, o gênero foi desmembrado e delimitado pelas sinapomorfias do pólen colporado e dos frutos com mesocarpo carnoso (Delprete, 2010). Os frutos são geralmente adocicados e usados como recurso alimentar por moradores de comunidades rurais, como os frutos de Cordiera macrophylla (K. Schum.) Kuntze (Pasa et al., 2005). Essa espécie é comumente conhecida como marmelada-de-bezerro, marmelada-espinho, entre outros (Delprete, 2010).

Contudo, os estudos sobre essa espécie são escassos, sendo necessários trabalhos para o conhecimento dos eventos fenológicos de floração e frutificação, da biologia floral, a determinação do papel dos vetores de fluxo de pólen, além do entendimento do sistema reprodutivo. Esses são pontos fundamentais para a compreensão da biologia reprodutiva das espécies e para o início do desenvolvimento de programas de melhoramento genético (Maués \& Couturier, 2002).

Considerando-se a inexistência de estudos abordando os aspectos da biologia reprodutiva de Cordiera macrophylla, este trabalho se propõe a: i) estudar a fenologia reprodutiva, ii) conhecer a razão sexual, iii) descrever morfologia e a biologia floral, iv) conhecer o sistema reprodutivo e quantificar o sucesso reprodutivo em dois fragmentos de Floresta Estacional Semidecidual, no município de Tangará da Serra, MT.

\section{MATERIAL E MÉTODOS}

\section{Áreas de estudo}

O município de Tangará da Serra (1404'S e 5703'W), altitude média de 423 m está localizado na região sudoeste do Estado de Mato Grosso, Brasil. O clima é caracterizado como tropical chuvoso quente e úmido, com duas estações bem definidas: chuvas, entre Outubro e Abril, e seca, de Junho a Agosto. Apresenta precipitação média anual de cerca $1.830 \mathrm{~mm}$, a temperatura média é de $24{ }^{\circ} \mathrm{C}$ e, a umidade relativa do ar de 70 a $80 \%$ (Martins et al., 2010). Os solos da região são do tipo Latossolo Vermelho distroférrico de textura muito argilosa. A vegetação é uma transição entre os biomas Floresta Amazônica e Cerrado e atualmente encontra-se fragmentada pela implantação de monoculturas.

Os trabalhos de campo foram conduzidos entre os meses de Julho e Novembro, durante os anos de 2010 e 2011, em dois Fragmentos Florestais de Mata Estacional Semidecidual (Sasaki et al., 2010), distantes entre si cerca de $1 \mathrm{Km}$. Os critérios adotados para a seleção dos fragmentos foram a fitofisionomia e o estádio de sucessão secundária. O Fragmento Mata Queimada (FMQ) $\left(14^{\circ} 39^{\prime} 05^{\prime} \mathrm{S}\right.$ e $\left.57^{\circ} 25^{\prime} 25^{\prime} \mathrm{W}\right)$ conta aproximadamente com 18 ha e apresenta atividades antrópicas como: incêndio, pisoteio de gado e, no seu entorno, implantação de pastagens e, eventualmente, monocultura de soja. $\mathrm{O}$ Fragmento Autódromo (FA) (14³9'34" S e 57²6’01" W) soma cerca de sete ha, está circundado por pastagens e, invariavelmente, seu interior sofre pisoteio por rebanhos bovinos.

\section{Fenologia de floração}

A fenologia de floração de Cordiera macrophylla foi acompanhada, semanalmente, em oito indivíduos estaminados e em cinco pistilados, de cada fragmento. Por causa do porte arbustivo ou arbóreo da espécie, os dados fenológicos foram registrados em três ramos por indivíduo. Para os ramos de indivíduos estaminados, foi quantificado o número de inflorescências por ramo, flo- 
res por inflorescência e flores abertas por inflorescência. Para os ramos pistilados, quantificou-se o número de flores produzidas por ramo e flores abertas por inflorescência. Durante a frutificação, oriunda de polinização natural, foi registrado o número de frutos produzidos por ramo de cada indivíduo, nos dois fragmentos. Espécimes testemunhas de Cordiera macrophylla foram depositados no herbário da Universidade do Estado de Mato Grosso, campus de Tangará da Serra, MT (TANG 1240).

A determinação da razão sexual de Cordiera macrophylla foi realizada no ano de 2011, no FMQ. Para tanto, foram identificados, marcados, sexados e contados todos os indivíduos em fase reprodutiva. Para evitar a amostragem de indivíduos clonais, foram avaliados apenas os indivíduos com três metros de distância entre si, de acordo com a metodologia de Koch et al. (2010).

\section{Biologia floral}

A biologia floral foi acompanhada em 40 botões (26 estaminados e 14 pistilados). Para tanto, inflorescências com botões em pré-antese foram coletadas e observadas em laboratório e em campo. Para a longevidade, as flores foram observadas a cada hora e anotados o horário de início de antese (caracterizado pela separação dos lacínios da corola), período de liberação dos grãos de pólen até a senescência das flores (caracterizada pela perda da receptividade estigmática, escurecimento das pétalas e abscisão do tubo da corola).

O período de receptividade estigmática foi verificado em flores estaminadas e pistiladas; nas flores estaminadas, a receptividade estigmática foi avaliada no pistilódio. As avaliações foram realizadas em dez botões em pré-antese e em flores abertas de indivíduos masculinos $(\mathrm{N}=5)$ e femininos $(\mathrm{N}=5)$ e acompanhadas até a senescência, utilizando-se o peróxido de hidrogênio a 3\% (Dafni, 1994).

A viabilidade dos grãos de pólen foi avaliada em 25 botões em pré-antese, coletados de cinco indivíduos diferentes, em cada fragmento. Os botões foram estocados em ácido acético e, posteriormente, todas as anteras de cada botão floral foram maceradas em lâmina, sobre uma gota de Carmim Acético (Radford et al., 1974). As lâminas montadas foram observadas em microscópio óptico, na objetiva de 10 X. Em cada lâmina foram contados até 200 grãos de pólen (Koch et al., 2010).

A presença de osmóforos foi testada, utilizando-se a técnica de coloração com Vermelho-Neutro (Dafni, 1994) em 20 flores (10 estaminadas e 10 pistiladas), coletadas de cinco indivíduos diferentes. Flores frescas foram imersas em solução durante 15 minutos e, após, foram lavadas com água destilada, observadas e fotografadas em estereomicroscópio Leica ${ }^{\circledR}$ S6D. As regiões coradas de vermelho intenso indicaram a localização das células produtoras de odor.

\section{Morfologia floral}

O estudo da morfologia floral foi realizado nas flores estaminadas $(\mathrm{N}=25)$ e pistiladas $(\mathrm{N}=25)$, coletadas de cinco indivíduos diferentes para cada sexo. As flores foram analisadas e descritas após observações. As avaliações da morfometria floral foram realizadas em 25 flores de cada sexo, para cada fragmento $(\mathrm{N}=100)$, coletadas em diferentes indivíduos. Para a morfometria, as flores foram mantidas em álcool 70\%. Com papel milimetrado e estereomicroscópio, foram mensurados as seguintes características: altura dos estames, pistilo e cálice, altura e diâmetro do tubo da corola e lacínios. Para as análises morfológicas e morfométricas dos frutos, foram coletados 25 frutos desenvolvidos no (FA) e 15 no (FMQ) e, com paquímetro, foram mensuradas a altura e a largura dos frutos.

\section{Sistema reprodutivo}

O sistema reprodutivo foi avaliado apenas nos indivíduos pistilados, pois, nas flores dos estaminados foi constatada a ausência de ovário e de receptividade estigmática do pistilódio. Para o tratamento de apomixia, 30 botões em pré-antese, de cinco indivíduos, foram isolados com sacos de organza e acompanhados até a posterior produção de frutos. Para quantificar a polinização natural, 40 flores tiveram seus pedicelos marcados e permaneceram expostas aos visitantes florais, até a queda da flor ou, até o desenvolvimento dos frutos. Os frutos resultantes dos tratamentos acima citados e que completaram seu desenvolvimento, foram coletados e, o número de sementes por frutos, contado. O sucesso reprodutivo, definido como a produção de frutos e sementes (Dafni, 1994), foi quantificado, no ano de 2010, em três ramos de seis indivíduos diferentes (três indivíduos de cada fragmento) e, no ano de 2011, em cinco indivíduos por fragmento. A estimativa do sucesso reprodutivo (produção total de sementes por planta) foi obtida pela multiplicação do número médio de frutos por indivíduo, pelo número médio de sementes por fruto.

\section{Análises estatísticas}

O número de flores por inflorescência, em inflorescências estaminadas e pistiladas de cada fragmento analisado, foi submetido à análise de variância (Anova) por meio do programa Statistica versão 10 (Statsoft, 2010). Foi realizado o teste F, seguido da média e desvio padrão. Para melhorar a normalidade e homocedasticidade, os dados de grãos de pólen foram transformados em log, antes de prosseguir com a análise. 


\section{RESULTADOS}

Cordiera macrophylla apresentou um único episódio reprodutivo nas áreas de estudo. O início da floração ocorreu no final do mês de Julho de 2011 (estação seca) e o encerramento no final de Setembro (início da estação chuvosa). Em ambos os fragmentos florestais, as flores estaminadas iniciaram o florescimento antes das pistiladas, aproximadamente na última semana de Julho, prolongando-o até a terceira semana de Setembro. Os indivíduos pistilados apresentaram floração restrita ao mês de Agosto, no FMQ, e até a segunda semana de Setembro, no FA. O pico de floração foi sincrônico entre as flores estaminadas e pistiladas e ocorreu entre a segunda e a terceira semana de Agosto (Figura 1 A e B).

Flores de C. macrophylla apresentaram morfometrias florais semelhantes entre os fragmentos florestais. No entanto, as flores pistiladas exibiram tubo da corola ligeiramente maior que o das pistiladas (Tabela 1; Figura 2).

Não houve diferença significativa no número de inflorescências estaminadas, por ramo, nos fragmentos estudados $(\mathrm{F}=0,07 ; \mathrm{P}=0,79)$. C. macrophylla apresentou entre 2 e 15 inflorescências $(\overline{\mathbf{X}}=7,50 \pm 3,62$ no FA) e de 3 a 22 ( $\overline{\mathbf{X}}=7,92 \pm 4,49$, no FMQ). No entanto, o número de flores por inflorescência foi significativamente maior no FA $(\mathrm{F}=4,72 \mathrm{P}=0,04)$. Cada inflorescência abrigou de 3 a 40 flores $(\overline{\mathrm{X}}=14,95 \pm 5,64 ; \mathrm{N}=$ 189), no FA, e de 2 a 23 flores $(\overline{\mathrm{X}}=11,65 \pm 4,70 ; \mathrm{N}=$ 189), no FMQ.

O número de flores pistiladas por ramo foi semelhante entre os fragmentos florestais estudados ( $\mathrm{F}=$ $0,70 ; \mathrm{P}=0,42)(\overline{\mathbf{X}}=3,53 \pm 1,81$, no FA, e de $\overline{\mathrm{X}}=4,4 \pm$ 1,99, no FMQ). A frutificação, nos anos de 2010 e 2011, em ambos os fragmentos, estendeu-se de Setembro a Novembro (estação chuvosa). No ano de 2010, o número de frutos produzidos por ramo (Tabela 2) foi significativamente diferente entre os fragmentos $(\mathrm{F}=52,55 \mathrm{P}$ $=0,002)$. O número de sementes por fruto não apresentou diferença significativa $(\mathrm{F}=3,39, \mathrm{P}=0,14)$. Características de número de frutos produzidos por ramo $(\mathrm{F}=$ $0,38 ; \mathrm{P}=0,55)$ e sementes por fruto $\mathrm{F}=0,41 ; \mathrm{P}=0,54$ não apresentaram diferença significativa entre os fragmentos, no ano de 2011 (Tabela 2).
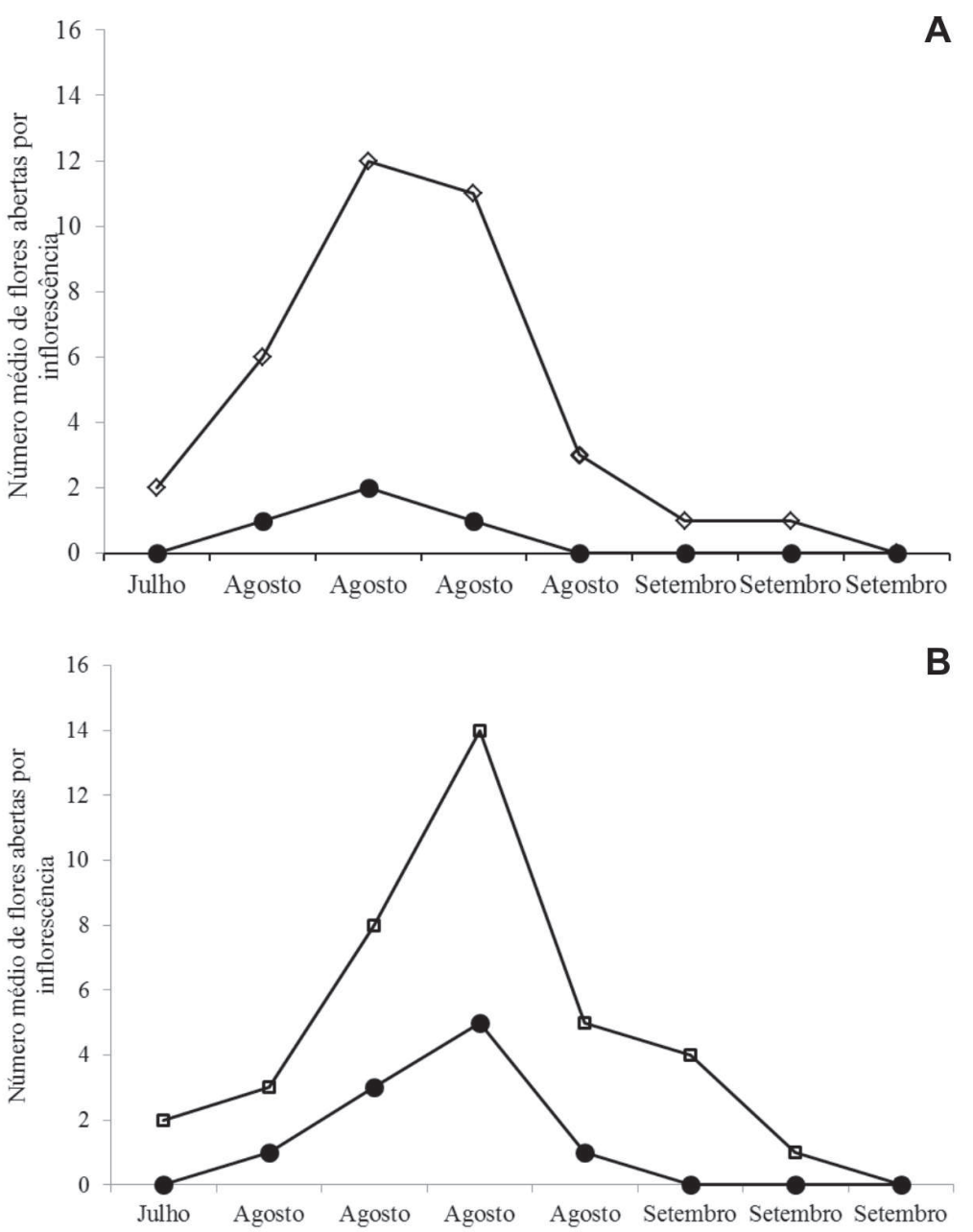

Figura 1: Número médio de flores estaminadas $(\diamond)$ e pistiladas $(\bullet)$ de Cordiera macrophylla (K. Schum.) Kuntze, no ano de 2011, no Fragmento Mata Queimada (A) e no Fragmento Autódromo (B), Tangará da Serra, MT. 
A razão sexual da população de C. macrophylla, no FMQ, foi de 12 indivíduos estaminados e 12 pistilados (1:1), caracterizando a população como isoplética.

A antese das flores de estaminadas de $C$. macrophylla ocorreu principalmente no final da manhã e, durante a tarde, nas pistiladas. Flores estaminadas apresentaram pico de abertura entre os horários de $9 \mathrm{~h}$ 30 min e 10 h 30 min, e longevidade de dois a três dias. A cerca de 24 horas do início da antese, as flores encontravam-se totalmente abertas e com os lacínios reflexos. Dois dias após antese, ocorreu a abscisão do tubo da corola.

Tabela 1: Morfometria de flores estaminadas (ð) e pistiladas (ㅇ) de Cordiera macrophylla (K. Schum.) Kuntze, no Fragmento Autódromo (FA) e no Fragmento Mata Queimada (FMQ), município de Tangará da Serra, MT ( $\overline{\mathbf{X}}=$ média; \pm desvio padrão)

\begin{tabular}{|c|c|c|c|c|c|}
\hline \multirow{2}{*}{ Sexo } & \multirow{2}{*}{ Estruturas mensuradas (cm) } & \multicolumn{2}{|c|}{ FA } & \multicolumn{2}{|c|}{ FMQ } \\
\hline & & $\overline{\mathbf{X}} \pm \mathbf{D P}$ & Variação & $\overline{\mathbf{X}} \pm \mathbf{D P}$ & Variação \\
\hline \multirow{5}{*}{$\delta$} & Altura do cálice & $0,25 \pm 0,06$ & $0,12-0,31$ & $0,34 \pm 0,04$ & $0,30-0,40$ \\
\hline & Altura do tubo da corola & $0,70 \pm 0,08$ & $0,56-0,82$ & $0,70 \pm 0,08$ & $0,54-0,82$ \\
\hline & Altura dos lacínios da corola & $0,40 \pm 0,07$ & $0,26-0,50$ & $0,49 \pm 0,03$ & $0,40-0,52$ \\
\hline & Altura das anteras & $0,56 \pm 0,06$ & $0,44-0,67$ & $0,55 \pm 0,06$ & $0,41-0,60$ \\
\hline & Altura do pistilódio & $0,73 \pm 0,06$ & $0,61-0,80$ & $0,76 \pm 0,08$ & $0,61-0,90$ \\
\hline \multirow{8}{*}{ 우 } & Altura do cálice & $0,16 \pm 0,05$ & $0,10-0,21$ & $0,16 \pm 0,04$ & $0,10-0,22$ \\
\hline & Altura do tubo da corola & $0,64 \pm 0,10$ & $0,40-0,80$ & $0,67 \pm 0,09$ & $0,50-0,90$ \\
\hline & Altura dos lacínios da corola & $0,55 \pm 0,09$ & $0,38-0,70$ & $0,57 \pm 0,05$ & $0,50-0,68$ \\
\hline & Altura do estilete & $0,37 \pm 0,10$ & $0,20-0,60$ & $0,40 \pm 0,08$ & $0,30-0,60$ \\
\hline & Altura do estigma & $0,45 \pm 0,07$ & $0,30-0,60$ & $0,43 \pm 0,07$ & $0,30-0,51$ \\
\hline & Altura do ovário & $0,50 \pm 0,10$ & $0,30-0,70$ & $0,53 \pm 0,10$ & $0,30-0,70$ \\
\hline & Largura do ovário & $0,45 \pm 0,06$ & $0,35-0,60$ & $0,44 \pm 0,07$ & $0,32-0,58$ \\
\hline & Altura dos estaminódios & $0,34 \pm 0,05$ & $0,21-0,45$ & $0,40 \pm 0,01$ & $0,37-0,42$ \\
\hline
\end{tabular}
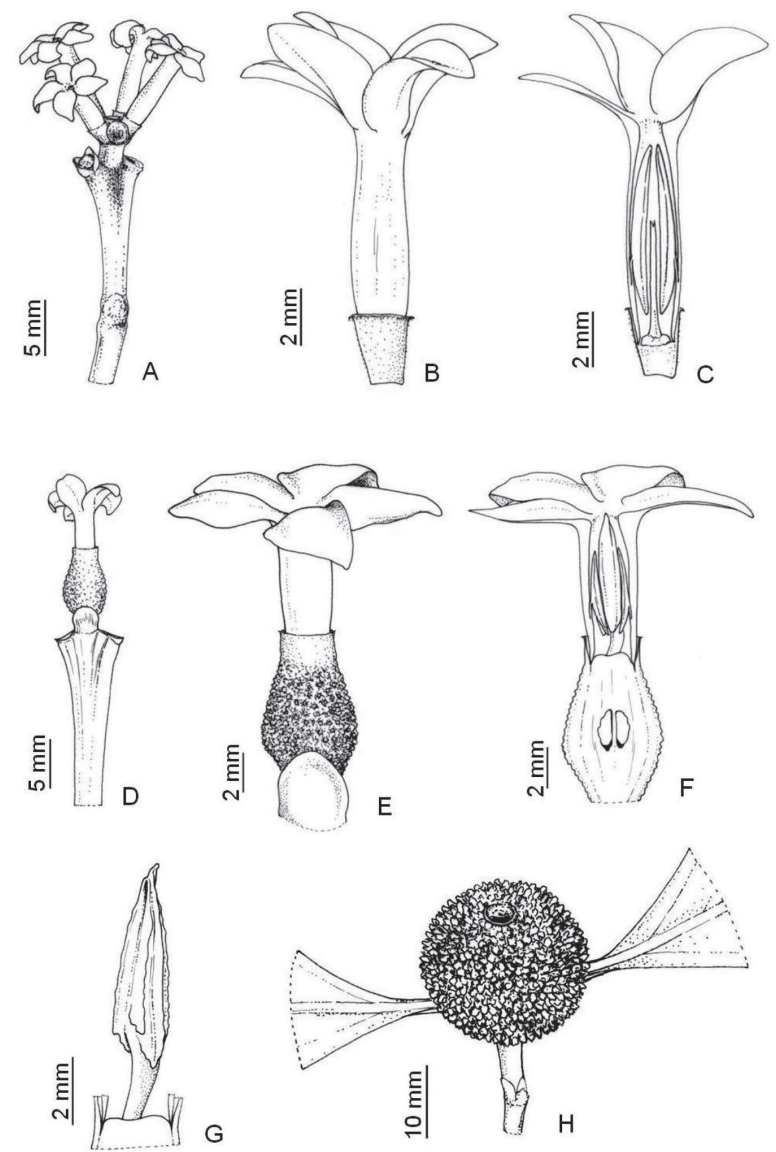

Figura 2: Cordiera macrophylla: A. Inflorescência estaminada; B-C. Morfologia da flor estaminada; D. Flor pistilada uniflora; E-F. Morfologia da flor pistilada; G. Estigma. H. Fruto verrucoso. 
As flores pistiladas apresentaram pico de abertura entre $14 \mathrm{e} 15 \mathrm{~h}$ e longevidade maior que as estaminadas, de cinco a seis dias. Aproximadamente 48 horas após o início da antese, os lacínios da corola apresentavam-se reflexos. O cálice permaneceu aderido ao ovário durante o desenvolvimento dos frutos e durante alguns dias ainda era possível observar néctar em pequenas quantidades no ápice do ovário.

Os estames rudimentares não apresentaram grãos de pólen e o teste de peroxidase revelou que o estigma apresentava-se receptivo, da pré-antese até a senescência. O pólen foi liberado desde a pré-antese até a senescência floral. Nas flores estaminadas, não foi observada receptividade do pistilódio, na pré-antese e na antese. A viabilidade polínica das flores estaminadas foi alta $(86,72 \%$, no FA) e (76\%, no FMQ). Flores de C. macrophylla são aromáticas, exalando um odor suave e adocicado após a antese. A técnica de coloração com vermelho-neutro indicou a presença de osmóforos nos lacínios das pétalas das flores estaminadas e pistiladas.

As flores de C. macrophylla apresentaram características semelhantes entre flores estaminadas e pistiladas. Ambas são terminais, diclamídeas, sésseis e localizadas entre um par de folhas (Figura 2A-D). O cálice é truncado, gamossépalo, com disco nectarífero; corola gamopétala tubular (Figura 2-E), esbranquiçada, actinomorfa, hipocrateriforme, o tubo da corola e os lacínios são subcoriáceos e esverdeados.

As flores estaminadas são produzidas em inflorescências umbeliformes (Figura 2A), corola 4-5 lacínios (Figura 2B). O androceu é composto de 4 a 5 estames inclusos no tubo da corola, sésseis, epipétalos, dorsifixos, estreito-oblongados (Figura 2C), com anteras bitecas e deiscência rimosa. O estilete é rudimentar, com lobos estigmáticos fundidos e ausência de ovário (Figura 2C). Flores pistiladas são unifloras (Figura 2D), corola de 4 a 7 lacínios (Figura 2E); estigma 2-3 lobulado; ovário ínfero, globoso verrucoso, placentação axial, 3 a 4 lóculos, (Figura 2F) e estames estéreis (Figura $2 \mathrm{~F}$ ).
Os frutos são bagas globosas, verrucosas e solitárias, coroadas pelo cálice persistente (Figura 2H), de amarelo a castanho, na maturidade, com altura variando entre 2,5 e $3,4 \mathrm{~cm}(\overline{\mathrm{X}}=2,95 \pm 0,22)$ e largura de $3,1 \mathrm{a} 4,0$ $\mathrm{cm}(\overline{\mathrm{X}}=3,44 \pm 0,25)$, no FA e de 2,7 a $3,5 \mathrm{~cm}(\overline{\mathrm{X}}=3,09$ $\pm 0,24)$ e de 2,8 a $4,1 \mathrm{~cm}(\bar{X}=3,49 \pm 0,38)$, no FMQ, respectivamente.

A formação de frutos por polinização natural ocorreu em $95 \%$ das flores marcadas. Foi observado início de desenvolvimento de frutos por apomixia em 26,67\% das flores, esses frutos eram aparentemente menores, apresentando em média ( $=0,73 \mathrm{~cm} \pm 0,10$ de altura) e $(\overline{\mathrm{X}}=0,56 \mathrm{~cm} \pm 0,04$ de largura) e exibiram abscisão antes de alcançar a maturação. Nos dois fragmentos estudados, as avaliações realizadas para os frutos apresentaram resultados semelhantes, nos dois anos de observação da espécie.

\section{DISCUSSÃO}

O período de floração de $C$. macrophylla durante a estação seca difere do padrão observado para espécies arbóreas do Cerrado brasileiro, nas quais esta fenofase está diretamente relacionada com o início da estação chuvosa (Oliveira \& Gibbs, 2000), em que mudanças na pluviosidade, na temperatura e fotoperíodo funcionam como sinais ambientais para a floração, mas não são determinantes restritos (Oliveira, 1998), de forma que é possível encontrar espécies florescendo durante todo o ano (Oliveira \& Gibbs, 2002).

Neste estudo, o pico de floração das flores estaminadas e pistiladas ocorreu sincronicamente, e essa é uma característica comum em espécies dioicas, uma vez que os indivíduos estaminados investem mais na produção de flores que os pistilados (Bawa, 1980), favorecendo os indivíduos femininos pela presença de visitantes (Piratelli et al., 1998). Além disso, o maior display de flores estaminadas, comparado com o das pistiladas, assegura a atração e manutenção dos polinizadores, garantindo assim o sucesso reprodutivo da espécie (Jardim \& Mota, 2007).

Tabela 2: Médias e desvio padrão do número de frutos e sementes produzidos de polinizações naturais em Cordiera macrophylla (K. Schum) Kuntze, no Fragmento Autódromo (FA) e no Fragmento Mata Queimada (FMQ), Tangará da Serra, MT. ( $\overline{\mathbf{X}}=$ média, \pm desvio padrão)

\begin{tabular}{|c|c|c|c|c|c|c|c|c|}
\hline \multirow{3}{*}{$\begin{array}{l}\text { Características } \\
\text { analisados }\end{array}$} & \multicolumn{4}{|c|}{2010} & \multicolumn{4}{|c|}{2011} \\
\hline & \multicolumn{2}{|c|}{ FA } & \multicolumn{2}{|c|}{ FQM } & \multicolumn{2}{|c|}{ FA } & \multicolumn{2}{|c|}{ FQM } \\
\hline & $\overline{\mathrm{X}} \pm \mathrm{DP}$ & Variação & $\overline{\mathrm{X}} \pm \mathrm{DP}$ & Variação & $\overline{\mathrm{X}} \pm \mathrm{DP}$ & $\overline{\text { Variação }}$ & $\overline{\mathrm{X}} \pm \mathrm{DP}$ & Variação \\
\hline Frutos/ramo & $2,3 \pm 0,5$ & $2-3$ & $5,5 \pm 1,3$ & $4-8$ & $3,4 \pm 1,3$ & $2-5$ & $3,9 \pm 1,4$ & $2-5$ \\
\hline Frutos/Ind. & $7,0 \pm 1,0$ & $6-8$ & $16,7 \pm 2,1$ & $15-19$ & $10,2 \pm 1,1$ & $3-15$ & $11,8 \pm 2,7$ & $8-12$ \\
\hline Sementes/fruto & $32,2 \pm 6,1$ & $17-41$ & $28,3 \pm 3,9$ & $21-37$ & $28,3 \pm 2,2$ & $25-35$ & $26,5 \pm 5,8$ & $21-32$ \\
\hline Sementes /indivíduo & $225,3 \pm 10,0$ & $214-233$ & $472,0 \pm 40,4$ & $418-510$ & $288,6 \pm 2,8$ & $160-313$ & $312,6 \pm 1,8$ & $308-352$ \\
\hline
\end{tabular}


Os números de frutos e de sementes produzidos por indivíduo de C. macrophylla, nos dois fragmentos florestais estudados, é considerado alto, quando comparado com os de outras espécies dioicas de Cerrado, cuja percentagem de frutificação variou entre 0,5 e 9\% (Oliveira, 1996; Lenza \& Oliveira, 2005).

A isopletia é uma condição desejável em espécies dioicas, para evitar competição intersexual por polinizadores, pelo fato de as plantas estaminadas produzirem mais flores que as pistiladas. Segundo Bawa \& Opler (1975), os fatores que contribuem para a distribuição da proporção de plantas dioicas são o número de flores por inflorescência, de inflorescências por planta e de plantas com flores estaminadas e pistiladas, como observada em C. macrophylla. Em populações naturais, a anisopletia implica a distribuição desigual do número de gametas, favorecendo deste modo o sexo mais abundante (Zanon et al., 2009).

A diferença temporal entre o início da antese das flores parece ser uma característica vantajosa, pois quando as flores pistiladas começarem a abrir já haverá liberação de pólen pelas flores estaminadas, maximizando as oportunidades de transporte destes para o estigma.

A maior longevidade das flores pistiladas, em comparação com a das estaminadas está comumente associada à dioicia, sendo uma forma de aumentar o tempo de exposição aos agentes polinizadores, consequentemente, aumentando as chances de polinização (Lenza \& Oliveira, 2006; Ostrorog \& Barbosa, 2009), característica também observada em outras espécies dioicas, como Jacaratia spinosa - Caricaceae (Piratelli et al., 1998), Virola surinamensis - Myristicaceae (Jardim \& Mota, 2007), Tapirira guianensis - Anacardiaceae (Lenza \& Oliveira, 2005).

Alta viabilidade polínica foi observada em outras espécies dioicas, como Amaioua guianensis - Rubiaceae (Amorim \& Oliveira, 2006), Schinus terebinthifolius Anacardiaceae (Lenzi \& Orth, 2004), Protium spruceanum - Burseraceae (Vieira et al., 2010), Jacaratia spinosa - Caricaceae (Piratelli et al., 1998), Trichilia sp.- Meliaceae (Morellato, 2004). O período prolongado de receptividade estigmática das flores pistiladas, acompanhado da alta viabilidade polínica e do prolongamento do tempo de liberação de pólen das flores estaminadas maximizam as chances de fecundação dos óvulos.

As semelhanças morfológicas entre flores estaminadas e pistiladas de $C$. macrophylla, como a coloração clara e pouco conspícua, são atributos comuns em plantas dioicas (Bawa \& Opler, 1975; Bawa, 1980). Além disso, essas características correspondem ao padrão de cores e de formas florais de espécies do Cerrado
(Silberbauer-Gottesberger \& Gottesberger, 1988). A presença de estruturas vestigiais do sexo oposto pode estar relacionada com a teoria de Yamplosky \& Yamplosky (1966) e Bawa (1980), que relatam que dioicia pode ter evoluído a partir de ancestrais hermafroditas ou via ancestrais ginodioicos, androdioicos ou monoicos e, em alguns casos, por heterostilia, ocorrendo a supressão de estruturas reprodutivas do sexo masculino ou do feminino em diferentes indivíduos. Em alguns casos, no entanto, indivíduos de um sexo produzem estruturas sexuais do sexo oposto (Pessoa et al., 2013).

A presença de apomixia em C. macrophylla conferiria vantagens à espécie, possibilitando a colonização de novos ambientes, mesmo na ausência de polinizadores. Amorim \& Oliveira (2006) também observaram, em Amaioua guianensis (Rubiaceae), o desenvolvimento apomítico de frutos $(11,16 \%)$, sendo que destes apenas $3,4 \%$ alcançaram maturação, porém eram menores e atrofiados. Baixa produção de frutos por apomixia foi relatada para outras espécies dioicas, como Tapirira guianensis-Anacardiaceae (Lenza \& Oliveira, 2005), Jacaratia spinosa - Caricaceae (Piratelli et al., 1998).

Características morfométricas e morfológicas, aliadas ao sincronismo de floração entre flores pistiladas e estaminadas, nos dois episódios reprodutivos, garantiram resultados semelhantes entre o sucesso reprodutivo, em ambos os fragmentos florestais estudados. Os resultados indicam que a reprodução sexuada de $C$. macrophylla é dependente de agentes bióticos e que, embora os fragmentos florestais analisados apresentem forte pressão antrópica, eles ainda mantêm a fauna antófila, garantindo o fluxo de pólen entre as plantas. Estudos posteriores sobre o papel dos agentes polinizadores e dispersores, germinação de sementes e estratégias de estabelecimentos de novos indivíduos são necessários, para melhor compreensão do papel ecológico da espécie.

\section{CONCLUSÕES}

A floração de Cordiera macrophylla limitou-se a três meses do ano, durante a estação seca e início da estação chuvosa. Nos dois fragmentos estudados, houve sincronia no pico de floração entre flores estaminadas e pistiladas. Flores estaminadas e pistiladas apresentam semelhanças de tamanho e coloração.

A maior percentagem de frutos foi obtida por meio da polinização natural e houve baixa taxa de formação de frutos apomíticos. A semelhança do sucesso reprodutivo em ambos os fragmentos florestais estudados reforça a importância da conservação desses fragmentos para a manutenção da espécie. 


\section{AGRADECIMENTOS}

Agradecemos à Prof ${ }^{a}$ Zefa Valdivina Pereira da Universidade Federal de Dourados- MS, pela identificação de Cordiera macrophylla. À Prof ${ }^{a}$ Edenir Maria Serigatto e ao Prof $^{\circ}$ Abílio Luiz Colognese pelas críticas e sugestões ao manuscrito. Ao Reinaldo Pinto, pela confecção da prancha das flores.

\section{REFERÊNCIAS}

Amorim FW \& Oliveira PE(2006) Estrutura sexual e ecologia reprodutiva de Amaioua guianensis Aubl. (Rubiaceae), uma espécie dióica de formações florestais de cerrado. Revista Brasileira de Botânica, 26:353-362.

Barbosa MR, Taylor C, Cabral E, Jardim JG, Pereira MS, Calió MF, Pessoa MCR, Salas R, Souza EB, Di Maio FR, Macias L, Anunciação EA, Germano Filho P, Oliveira JÁ, Bruniera CP, Gomes M, De Toni K, Firens M \& Zappi D (2015) Rubiaceae. Disponível em: <http:// floradobrasil.jbrj.gov.br/jabot/floradobrasil/FB210>. Acessado em: 03 de fevereiro de 2015.

Bawa KS (1980) Evolution of dioecy in flowering plants. Annual Reviews of Ecology and Systematics, 11:15-39.

Bawa KS \& Opler PA (1975) Dioecism in tropical forest trees. Evolution, 29:167-179.

Dafni A (1994) Pollination ecology - A practical approach. Oxford, Oxford University Press. 260p.

Delprete PG (2010) Rubiaceae - Parte 2: Gêneros I-R. In: Rizzo JA (Ed.) Flora dos estados de Goiás e Tocantins. Goiânia, Universidade Federal de Goiás. 1097p.

Geber MA, Dawson TE \& Delph LF (1999) Gender and sexual dimorphism in flowering plants. New York, Springer. 305p.

Jardim MAG \& Mota CG (2007) Biologia floral de Virola surinamensis (Rol.) Warb. (Myristicaceae). Revista Árvore, 31:1155-1162.

Koch AK, Silva PC \& Silva CA (2010) Biologia reprodutiva de Psychotria carthagenensis (Rubiaceae), espécie distílica de fragmento florestal de mata ciliar, Centro-Oeste do Brasil. Rodriguesia, 61:551-558.

Lenza E \& Oliveira PE (2005) Biologia reprodutiva de Tapirira guianensis Aubl. (Anacardiaceae), uma espécie dióica em mata de galeria do Triângulo Mineiro, Brasil. Revista Brasileira de Botânica, 28:179-190.

Lenza E \& Oliveira PE (2006) Biologia reprodutiva e fenologia de Virola sebifera Aubl. (Myristicaceae) em mata mesofítica de Uberlândia, MG, Brasil. Revista Brasileira de Botânica, 29:443-451.

Lenzi M \& Orth AH (2004) Caracterização funcional do sistema reprodutivo da aroeira-vermelha (Schinus terebinthifolius Raddi), em FlorianópolisSC, Brasil. Revista Brasileira de Fruticultura, 26:198-201.

Martins JÁ, Dallacort R, Inoue MH, Santi A, Kolling EM \& Coletti AJ (2010) Probabilidade de precipitação para a microrregião de Tangará da Serra, Estado do Mato Grosso. Pesquisa Agropecuária Tropical, 40:291-296.

Maués MM \& Couturier G (2002) Biologia floral e fenologia reprodutiva do camu-camu (Myrciaria dúbia (H.B.K.) McVaugh, Myrtaceae) no Estado Pará, Brasil. Revista Brasileira de Botânica, 25:441-448.

Morellato LPC (2004) Phenology, sex ratio, and spatial distribuition among dioecious species of Trichilia (Meliaceae). Plant Biology, 6:491-497.

Oliveira PE \& Gibbs PE (2002) Pollination and reproductive biology in cerrado plant communities. In: Oliveira PE \& Marquis RJ (Eds.) The cerrados of Brazil: Ecology and Natural History of a Neotropical Savanna. Columbia University, New York. p.329-348.
Oliveira PE (1996) Dioecy in the Cerrado vegetation of Central Brasil. Flora, 191:235-243.

Oliveira PE (1998) Fenologia e biologia reprodutiva de espécies de Cerrado. In: Sano SM \& Almeida SP (Eds.) Cerrado: ambiente e flora. Planaltina, Embrapa-CPAC. p.170-192.

Oliveira PE \& Gibbs PE (2000) Reproductive biology of woody plants in a cerrado community of Central Brazil. Flora, 195:311-329.

Ostrorog DRV \& Barbosa AAA (2009) Biologia reprodutiva de Geonoma brevispatha Barb. Rodr. (Arecaceae) em mata de galeria inundável em Uberlândia, MG, Brasil. Revista Brasileira de Botânica, 32:479488.

Pasa MC, Soares JJ \& Guarim-Neto G (2005) Estudo etnobotânico na comunidade de Conceição-Açu (Alto da bacia do Aricá Açu, MT, Brasil). Acta Botânica Brasilica, 19:195-207.

Persson C (2000) Phylogeny of the Neotropical Alibertia group (Rubiaceae), with emphasis on the genus Alibertia, inferred from its and 5S ribosomal DNA sequences. American Journal of Botany, 87:1018-1028.

Pessoa SPM, Moraes JQ \& Silva CA (2013) Apomixia facultativa em Smilax fluminensis Steud. (Smilacaceae), espécie dioica de fragmentos florestais, Centro Oeste do Brasil. Revista Árvore, 37:1025-1035.

Piratelli AJ, Piña-Rodrigues FCM, Gandara FB, Santos EMG \& Costa LGS (1998) Biologia da polinização de Jacaratia spinosa (Aubl) ADC. (Caricaceae) em Mata Residual do Sudeste Brasileiro. Revista Brasileira de Biologia, 58:671-679.

Radford AE, Dickson WC, Massey JR \& Bell CR (1974) Vascular plant systematics. New York, Harper e Row. 891p.

Renner SS \& Ricklefs RE (1995) Dioecy and its correlates in the flowering plants. American Journal of Botany, 82:596-606.

Sasaki D, Zappi D, Milliken W, Henicka GS \& Piva JH (2010) Vegetação e plantas do Cristalino: um manual. Alta Floresta, Royal Botanic Gardens. 53p.

Silberbauer-Gottsberg I \& Gottsberger G (1988) A polinização de plantas do Cerrado. Revista Brasileira de Biologia, 48:651-663.

Statsoft, Inc. (2010) Statistica (data analysis software system), version 10. CD-ROM.

Vieira FA, Appolinário V, Fajardo CG \& Carvalho D (2010) Reproductive biology of Protium spruceanum (Burseraceae), a dominant dioecious tree in vegetation corridors in Southeastern Brazil. Revista Brasileira de Botânica, 33:711-715.

Yampolsky C \& Yampolsky H (1966) Distribution of sex forms in the phanerogamic flora. $3^{\circ}$ ed. Leipzig, Gebrüder Borntraeger. 62p.

Zanon MLB, Finger CAG \& Schneider PR (2009) Proporção da dioicia e distribuição diamétrica de árvores masculinas e femininas de Araucaria angustifolia (Bertol.) Kuntze, em povoamentos implantados. Ciência Florestal, 19:425-431.

Zappi D (2015) Cordiera. Disponível em: <http://floradobrasil.jbrj.gov.br/ jabot/floradobrasil/FB13890>. Acessado em: 03 de Fevereiro de 2015. 